\title{
Implementasi Program Pinjaman Dana Bergulir Bagi Usaha Mikro Kecil Dan Menengah (UMKM) Di Kabupaten Banyumas
}

\author{
${ }^{1}$ Isna Rahmadani, ${ }^{2}$ Simin ${ }^{3}$ Dwiyanto Indiahono
}

\author{
Program Studi Administrasi Publik Universitas Jenderal Soedirman
}

\begin{abstract}
Implementation is a process of policy administering that affects the execution, contents, and the impacts. In order to find out whether or not a program is able to reach its goal, there needs to be a study on the policy implementation. A revolving fund loan program is a program that helps small, micro, and medium enterprises in Banyumas Regency in which the loan can be pulled back. The goal of this program is to strengthen the interest aspect for these enterprises to increase the potential of a productive society, the growth of the local economy, to spread out working opportunities that will impact on poverty alleviation in that society. This research focuses on the implementation of the revolving fund loans for the small, micro, and medium enterprises. Method that is used in this research is a qualitative method. This research is done in Banyumas area. The data analysis is done by using an interactive analysis. The result of the implementation shows that this program has not been implemented well. The receivers of this program think that it is a helpful one, especially in helping them grow their business. However, bad credits in this program are still taking place, and there has not been a proper solution up until today. This situation happens because the receivers of the fund are often disobedient in paying their credit. Furthermore, there is no intense supervision after the revolving funds are distributed to those enterprises.
\end{abstract}

Keywords: Program Implementation, Public Policy Implementation, revolving fund loans, bad credit.

\begin{abstract}
Abstrak
Implementasi merupakan proses pengadministrasian kebijakan yang mempunyai konsekuensi terhadap pelaksanaan, isi dan dampak suatu kebijakan. Untuk mengetahui bagaimana suatu program berhasil mencapai tujuan program atau tidak diperlukan studi implementasi kebijakan. Program Pinjaman Dana Bergulir merupakan bantuan pinjaman dana bergulir yang diberikan kepada pelaku Usaha Mikro, Kecil dan Menengah di Kabupaten Banyumas dan dapat ditarik kembali suatu saat. Tujuan program dana bergulir adalah untuk memperkuat aspek permodalan bagi UMKM, meningkatkan potensi usaha masyarakat produktif, pertumbuhan ekonomi daerah, memperluas lapangan pekerjaan yang pada akhirnya berdampak pada pengentasan kemiskinan di masyarakat. Penelitian ini terfokus pada implementasi program pinjaman dana bergulir bagi UMKM. Metode penelitian digunakan dalam penelitian ini adalah metode kualitatif. Penelitian ini dilakukan di wilayah Kabupaten Banyumas. Metode analisis data yang digunakan adalah metode analisis interaktif. Hasil penelitian implementasi program pinjaman dana bergulir bagi UMKM di Kabupaten Banyumas menunjukkan bahwa dalam pelaksanaan program pinjaman dana bergulir di Kabupaten Banyumas belum sepenuhnya berhasil. Para penerima program pinjaman dana bergulir merasa sangat terbantu khususnya dalam meningkatkan perkembangan usaha yang dimiliki. Kredit macet dalam pinjaman dana bergulir masih terjadi dan permasalahan tersebut belum dapat diselesaikan secara tuntas hingga saat ini. Kredit macet ini terjadi karena ketidakpatuhan penerima program dalam mengembalikan angsuran kredit dan pengawasan yang dilakukan aparat pelaksana program belum dilakukan secara optimal. Dalam hal ini pengawasan yang dilakukan setelah dana bergulir disalurkan kepada para pelaku UMKM penerima program.
\end{abstract}


Jurnal Ilmu Administrasi Negara (AsIAN) Vol. 08 No. 0I (Maret 2020)

Kata Kunci : Implementasi Program, Implementasi Kebijakan Publik, Pinjaman Dana Bergulir, Kredit Macet.

${ }^{*}$ Penulis Korespondensi
E-mail : isnarahmadani16@gmail.com 


\section{PENDAHULUAN}

Implementasi kebijakan dapat dipandang sebagai suatu proses melaksanakan keputusan kebijaksanaan. Implementasi kebijakan menjadi salah satu tahapan dalam lingkaran proses atau siklus kebijakan publik. Implementasi kebijakan adalah tahap yang penting dalam kebijakan. Tahap ini menentukan apakah kebijakan yang ditempuh benar-benar aplikabel di lapangan dan berhasil untuk menghasilkan output dan outcomes seperti yang direncanakan (Indiahono, 2009: 143).

Menurut James E. Anderson (2010:7) berpendapat kebijakan sebagai serangkaian tindakan yang mempunyai tujuan tertentu yang diikuti dan dilaksanakan oleh seorang pelaku atau sekelompok pelaku guna memecahkan suatu masalah tertentu. Pengertian ini memberikan pemahaman bahwa kebijakan dapat berasal dari seorang pelaku atau sekelompok pelaku yang berisi serangkaian tindakan yang mempunyai tujuan tertentu. Kebijakan ini diikuti dan dilaksanakan oleh seorang pelaku atau sekelompok pelaku dalam rangka memecahkan suatu masalah tertentu.

Kebijakan publik diturunkan menjadi program. Programprogram yang dilaksanakan pemerintah sekarang merupakan turunan dari kebijakan yang lebih luas di atasnya. Dengan dibentuk dan dilaksanakannya program, maka kebijakan akan lebih mudah diorganisir dan dilaksanakan.
Setiap program memiliki suatu konsekuensi dalam hal ini dapat berupa hasil, efek, maupun akibat dari program tersebut.

Untuk mengetahui bagaimana suatu program berhasil mencapai tujuan program atau tidak diperlukan studi implementasi kebijakan. Implementasi program bertujuan untuk mengetahui sejauhmana keberhasilan pelaksanaan program. Setelah program diimplementasikan dapat diukur keberhasilan dalam pencapaian tujuan program, menemukan kendala-kendala dalam implementasi program dan mengidentifikasi hambatan dalam implementasi.

Program pinjaman dana bergulir adalah program bantuan yang diberikan pemerintah dalam bentuk kredit bergulir kepada pelaku Usaha Mikro, Kecil dan Menengah di Kabupaten Banyumas dalam rangka perkuatan permodalan guna meningkatkan potensi usaha masyarakat produktif. Tujuan dari dilaksanakannya program pinjaman dan bergulir bagi pelaku UMKM adalah untuk meningkatkan akses pembiayaan UMKM, sebagai pengembangan investasi daerah, mendorong pertumbuhan ekonomi daerah dan memperluas penciptaan lapangan usaha serta menumbuhkan wirausaha baru dalam penyerapan tenaga kerja sehingga pada akhirnya akan bermuara pada pengentasan kemiskinan yang terjadi di masyarakat. 
Tabel 1. Data Penerima Dana Bergulir Bagi UMKM di Kabupaten Banyumas Tahun 2016-2019

\begin{tabular}{|c|c|c|c|c|c|}
\hline NO & Tahun & $\begin{array}{c}\text { Kelompok } \\
\text { (unit) }\end{array}$ & $\begin{array}{c}\text { Jumlah } \\
\text { Anggota }\end{array}$ & $\begin{array}{c}\text { Jumlah } \\
\text { Kecamatan }\end{array}$ & $\begin{array}{c}\text { Dana yang } \\
\text { Dikucurkan }\end{array}$ \\
\hline 1 & 2016 & $32 \mathrm{ukm}$ & 496 & 16 & 1.100 .000 .000 \\
\hline 2 & 2017 & $26 \mathrm{ukm}$ & 422 & 19 & 1.072 .000 .000 \\
\hline 3 & 2018 & $34 \mathrm{ukm}$ & 519 & 13 & 1.775 .000 .000 \\
\hline 4 & 2019 & $43 \mathrm{ukm}$ & 666 & 17 & 1.581 .000 .000 \\
\hline \multicolumn{2}{|c|}{ Total } & $135 \mathrm{ukm}$ & 2.103 & 65 & 5.528 .000 .000 \\
\hline
\end{tabular}

Sumber : Dinnakerkop UKM Kabupaten Banyumas 2016-2019

Dapat dilihat dari tabel 1 diatas bahwa jumlah kelompok penerima pinjaman dana bergulir dari tahun 2016-2019 tertinggi pada tahun 2019, yakni sebanyak 43 kelompok UKM yang tersebar di 17 kecamatan di Kabupaten Banyumas dengan total dana yang dikucurkan sebesar Rp 1.581.000.000. Besaran dana yang dikucurkan pada masing-masing kelompok berbeda-beda disesuaikan dengan jenis usaha yang dimiliki dan jumlah anggota dari masing-masing kelompok. Pada tahun 2019 terjadi pemangkasan dana yang dialokasikan untuk program pinjaman dana bergulir bagi UMKM, terlihat dari jumlah dana yang dikucurkan lebih sedikit dibandingkan tahun sebelumnya meskipun dengan jumlah kelompok penerima dana bergulir yang lebih banyak dibandingkan tahun sebelumnya. Hal ini membuktikan bahwa dalam pelaksanaan program pinjaman dana bergulir belum dapat dikatakan sepenuhnya berhasil sehingga membuat pemerintah lebih berhati-hati dalam mekanisme penyaluran pinjaman dana bergulir tersebut.

Tabel 2. Data Non Perfoming Loan Kredit Dana Bergulir Dinas Tenaga Kerja, Koperasi, dan UKM Kabupaten Banyumas Periode 2013-2018

\begin{tabular}{|c|c|c|c|c|}
\hline Tahun & $\begin{array}{c}\text { Jumlah } \\
\text { Rekenin } \\
\mathrm{g}\end{array}$ & Disalurkan & Bakidebet & Jumlah Tunggakan \\
\hline $\begin{array}{c}\text { Desembe } \\
\text { r } 2013\end{array}$ & 435 & $\begin{array}{c}8.020 .000 .00 \\
0\end{array}$ & $\begin{array}{c}3.500 .105 .37 \\
9\end{array}$ & 1.664 .627 .051 \\
\hline $\begin{array}{c}\text { Desembe } \\
\text { r } 2014\end{array}$ & 452 & 8.740 .000 .000 & $\begin{array}{c}3.371 .538 .83 \\
5\end{array}$ & 1.707 .387 .973 \\
\hline
\end{tabular}


Lanjutan tabel 2.

\begin{tabular}{|c|c|c|c|c|}
\hline Tahun & $\begin{array}{c}\text { Jumlah } \\
\text { Rekenin } \\
\mathrm{g} \\
\end{array}$ & Disalurkan & Bakidebet & Jumlah Tunggakan \\
\hline $\begin{array}{c}\text { Desember } \\
2016\end{array}$ & 491 & 9.510 .000 .000 & 2.416 .350 .471 & 2.758.991.681 \\
\hline $\begin{array}{l}\text { Septembe } \\
\text { r } 2017\end{array}$ & 523 & $\begin{array}{c}10.731 .000 .00 \\
0\end{array}$ & 3.408 .480 .545 & 2.824 .684 .072 \\
\hline $\begin{array}{l}\text { Septembe } \\
\text { r } 2018\end{array}$ & 350 & $\begin{array}{c}11.786 .500 .00 \\
0\end{array}$ & 3.963 .072 .443 & 2.433 .755 .978 \\
\hline Total & 2.251 & $\begin{array}{c}48.787 .500 .00 \\
0\end{array}$ & $\begin{array}{c}16.659 .547 .67 \\
3\end{array}$ & 11.389 .446 .755 \\
\hline $\begin{array}{l}\text { Dari } \\
\text { dikatakan } \\
\text { tentang pen } \\
\text { bergulir } \\
\text { dilaksanaka } \\
\text { dimana dan } \\
\text { dari Angga } \\
\text { Belanja Dae } \\
\text { Banyumas. } \\
\text { jumlah rek } \\
\text { bergulir } \\
\text { begitu juga } \\
\text { disalurkan s } \\
\text { terdapat tı }\end{array}$ & $\begin{array}{l}\text { tabel ter } \\
\text { bahwa } \\
\text { yaluran pi } \\
\text { bagi UI } \\
\text { n hingga } \\
\text { la tersebu } \\
\text { ran Penc } \\
\text { rah (APBD } \\
\text { Pada tahu } \\
\text { ening per } \\
\text { semakin } \\
\text { dengan } \\
\text { emakin m }\end{array}$ & $\begin{array}{l}\text { ebut dapat } \\
\text { kebijakan } \\
\text { jaman dana } \\
\text { KM telah } \\
\text { saat ini, } \\
\text { bersumber } \\
\text { patan dan } \\
\text { Kabupaten } \\
2013-2018 \\
\text { rima dana } \\
\text { bertambah } \\
\text { dana yang } \\
\text { ningkat dan } \\
\text { ada setiap }\end{array}$ & \multicolumn{2}{|c|}{$\begin{array}{l}\text { angsuran kredit disebabkan } \\
\text { karena berbagai hal. Permasalahan } \\
\text { lain dari pelaksanaan program } \\
\text { pinjaman dana bergulir adalah } \\
\text { kurangnya kesadaran atau } \\
\text { ketidakpatuhan pelaku UMKM } \\
\text { penerima program atas kewajiban } \\
\text { mengembalikan angsuran, dengan } \\
\text { permasalahan yang ada maka } \\
\text { peneliti tertarik untuk meneliti } \\
\text { implementasi program pinjaman } \\
\text { dana bergulir bagi pelaku Usaha } \\
\text { Mikro, Kecil dan Menengah } \\
\text { (UMKM) di Kabupaten Banyumas. }\end{array}$} \\
\hline
\end{tabular}

tahunnya. Pada tahun 2018, meskipun jumlah dana yang disalurkan paling banyak dengan jumlah rekening paling sedikit namun tunggakan tersebut masih terjadi. Dengan demikian diketahui bahwa dalam implementasi pinjaman dana bergulir ini cukup problematik.

Permasalahan yang timbul pada pelaksaksanaan program pinjaman dana bergulir bagi UMKM di Kabupaten Banyumas berdasarkan hasil pra survey, diketahui bahwa terjadinya kredit macet dalam pengembalian

\section{METODE PENELITIAN}

Penelitian ini dilaksanakan di wilayah Kabupaten Banyumas karena Kabupaten Banyumas merupakan salah satu Kabupaten yang menerapkan program pinjaman dana bergulir bagi UMKM. Sasaran penelitian ini adalah penerima program pinjaman dana bergulir (Pelaku Usaha Mikro, Kecil dan Menengah) di Kabupaten Banyumas. Sasaran penelitian juga ditujukan kepada pengelola program pinjaman dana 
bergulir dari Dinas Tenaga Kerja, Koperasi dan UKM Kabupaten Banyumas. Metode penelitian yang digunakan adalah metode penelitian kualitatif. Teknik pemilihan informan dalam penelitian ini menggunakan Purposive Sampling. Fokus dari penelitian ini adalah implementasi program pinjaman dana bergulir dilihat dari aspek karakteristik aparat pelaksana dan karakteristik kelompok sasaran. Metode analisis data yang digunakan adalah metode analisis interaktif yang dikembangkan oleh Miles dan Huberman yang terdiri dari pengumpulan data, kondensasi data, penyajian data serta verifikasi dan penarikan kesimpulan.

\section{HASIL PENELITIAN DAN PEMBAHASAN}

Penelitian ini menggunakan teori dari Randall B. Ripley. Untuk mengetahui informasi dan permasalahan yang berkaitan dengan fokus penelitian, didasarkan pada asumsi, pendapat, pandangan dan pemahanan informan dalam hal ini pemerintah, pengelola program pinjaman dana bergulir dan penerima program pinjaman dana bergulir terhadap fokus penelitian.

\section{Proses Penyeleksian Proposal Pengajuan Pinjaman Dana Bergulir}

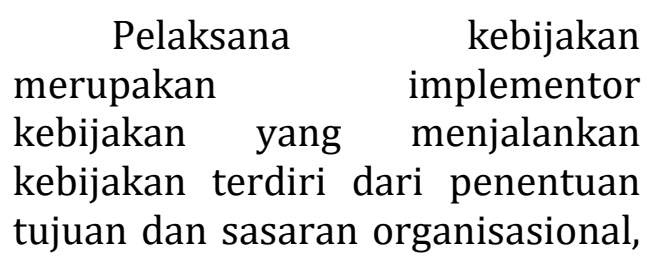

analisis serta perumusan kebijakan dan strategi organisasi, pengambilan keputusan, pengorganisasian, penggerakkan manusia, pelaksanaan operasional, pengawasan serta penilaian. Berdasarkan kesimpulan hasil penelitian bahwa program pinjaman dana bergulir bagi pelaku Usaha Mikro, Kecil dan Menengah di Kabupaten Banyumas dilihat dari segi pelaksana kebijakan telah dilaksanakan sesuai dengan Standar Operasional Prosedur (SOP) program.

Kepatuhan aparat pelaksana terhadap SOP penyaluran pinjaman dana bergulir ditunjukkan dengan melaksanakan proses seleksi proposal pengajuan pinjaman secara selektif sesuai petunjuk teknis dalam menetapkan calon penerima pinjaman dana bergulir. Selain itu, sikap kepatuhan juga dapat dilihat dari tingkat kepatuhan pelaksana kebijakan terhadap perintah atau mandat dari atasan untuk melaksanakan setiap prosedur yang ada.

Menurut Mazmanian
dan A. Sabatier (1983),
menyatakan bahwa ada tiga
variabel yang mempengaruhi
keberhasilan implementasi, yaitu
karakteristik masalah,
karakteristik aparat pelaksana dan
lingkungan. Karakteristik aparat
pelaksana didalamnya meliputi,
(1) kejelasan dan konsistensi
aturan yang ada pada badan
pelaksana, (2) tingkat komitmen
aparat terhadap tujuan kebijakan,
dan (3) seberapa besar adanya


keterpautan dan dukungan antar berbagai institusi pelaksana.

$$
\text { Kejelasan dan }
$$

konsistensi aturan yang ada pada badan pelaksana telah dilaksanakan dengan baik sesuai dengan SOP program oleh pengelola program, yaitu Dinas Tenaga Kerja, Koperasi dan UKM Kabupaten Banyumas. Terjalinnya hubungan koordinasi yang sinergi antara Dinas UKM Kabupaten Banyumas dengan instansi lain yang tergabung dalam Tim Pokja penyaluran pinjaman dana bergulir. Implementor dalam hal ini pengelola program tidak hanya sekedar mengetahui tugasnya, namun juga memberikan dukungan dan menunjukkan kemauan dengan sungguhsungguh dalam melaksanakan program agar tujuan program dapat tercapai.

Peran Dinas Tenaga Kerja, Koperasi dan UKM sebagai pengelola program sangat menentukan keberhasilan pelaksanaan program. Apabila pengelola program dalam melakukan tahap penyeleksian, verifikasi, penyaluran, dan pengawasan tidak dilaksanakan dengan baik maka dapat dikatakan implementasi program tersebut belum sepenuhnya berhasil. Dalam hal ini kegagalan dalam melakukan penyeleksian proposal pengajuan pinjaman dana bergulir mengakibatkan implementasi program pinjaman dana bergulir tidak berhasil, karena dapat dipastikan bahwa penerima program yang menjadi target group dalam program pinjaman dana bergulir tidak tepat sasaran.

\section{Respon Aparat Pelaksana terhadap Kredit Macet}

Karakteristik aparat pelaksana dengan sub aspek respon pengelola program terhadap kredit macet, yaitu diperlukan adanya sanksi yang tegas dalam menindaklanjuti permasalahan kredit macet pada penerima program. Sanksi yang diberikan pengelola program terhadap pelaku UKM penerima dana bergulir yang tidak lancar atau macet dalam pengembalian angsuran kredit berupa memberikan denda keterlambatan sebesar 2\%. Selain denda keterlambatan sanksi lainnya dengan memberikan teguran secara tulis dan lisan. Dengan adanya sanksi ini diharapkan dapat meminimalkan terjadinya kredit macet dalam implementasi program pinjaman dana bergulir di Kabupaten Banyumas.

$\begin{array}{crc}\text { Sejalan } & \text { dengan } & \text { hasil } \\ \text { penelitian } & \text { terdahulu } & \text { yang }\end{array}$
dilakukan oleh Chintya Fibri A. (2018:14) mengemukakan bahwa implementasi bantuan dana bergulir bagi pelaku usaha di Kota Tanjungpinang dapat dikatakan kurang berjalan dengan maksimal dan gagal. Hal ini dapat dilihat dari indikator-indikator yang mempengaruhi kebijakan sebagai berikut: (1) standart dan sasaran kebijakan menjadi panduan utama didalam menjalankan sebuah kebijakan. (2) Sumber daya finansial dan sumber daya manusia menjadi faktor 
pendukung lainnya di dalam pelaksanaan bantuan dana bergulir, (3) komunikasi antar badan pelaksana berjalan dengan baik dan mengikuti kondisi yang ada, (4) karakteristik badan pelaksana berarti merujuk pada ciri-ciri dari instansi yang melaksanakan sebuah kebijakan, dan (5) sikap pelaksana kebijakan dirasa diam dan tertutup untuk menjalankan keseluruhan.

Standar dan sasaran yang ada harus dapat dipahami oleh pelaksana kebijakan agar apa yang menjadi tujuan dan sasaran dapat tercapai. Aparat pelaksana dalam hal ini harus dapat memahami dengan benar apa yang menjadi standar dan sasaran program pinjaman dana bergulir. Sehingga, pada saat melakukan penyeleksian proposal pengajuan dana bergulir untuk menetapkan calon penerima dana bergulir tepat sasaran. Hal ini dikarenakan aparat pelaksana mengetahui apa yang menjadi sasaran dari program pinjaman dana bergulir.

Sikap pelaksana atau respon aparat pelaksana terhadap permasalahan kredit macet dalam implementasi program pinjaman dana bergulir cenderung bertindak dan lebih selektif dalam melakukan proses penyeleksian proposal pinjaman dana bergulir dengan lebih hati-hati. Bentuk kehati-hatian ini terlihat dengan adanya diskusi panjang dengan instansi lain dalam menetapkan calon pinjaman dana bergulir yang tergabung dalam Tim Pokja. Tindakan yang dilakukan Dinas Tenaga Kerja, Koperasi dan UKM
Kabupaten Banyumas dengan memberikan sanksi berupa denda keterlambatan dan teguran baik lisan maupun tertulis, memberikan kelonggaran batas waktu pengembalian angsuran serta tidak akan menggulirkan kembali dana bergulir bagi pelaku UKM penerima program yang kreditnya macet.

Berdasarkan pembahasan di atas dapat ditarik kesimpulan, bahwa pelaksanaan program pinjaman dana bergulir bagi pelaku Usaha Mikro, Kecil dan Menengah di Kabupaten Banyumas cukup baik. Namun, implementasi program pinjaman dana bergulir bagi pelaku UMKM di Kabupaten Banyumas belum dapat dikatakan sepenuhnya berhasil. Dinas Tenaga Kerja, Koperasi dan UKM Kabupaten Banyumas dalam hal ini dirasa cukup ketat dalam melakukan seleksi proposal pengajuan pinjaman dana bergulir oleh pelaku UMKM dengan melakukan beberapa pemeriksaan di lapangan untuk mengetahui kondisi rill dari pelaku UMKM.

Akan tetapi, aparat pelaksana dirasa kurang efektif dalam melakukan pengawasan atau pemeriksaan kepada pelaku UKM penerima dana bergulir yang macet dalam pengembalian angsuran kredit. Sehingga, membuat pelaku UKM penerima program menjadi lalai untuk melakukan kewajiban dalam mengembalikan angsuran kredit. Hal ini dikarenakan banyaknya jumlah pelaku UMKM penerima dana bergulir yang macet di 
Kabupaten Banyumas hingga saat ini, lebih khususnya untuk penerima program pada periode awal digulirkan membuat Dinas Tenaga Kerja, Koperasi dan UKM kurang bisa menjangkau secara keseluruhan dari pelaku UKM tersebut.

\section{Kriteria Pelaku UMKM Penerima Pinjaman Dana Bergulir}

Kelompok sasaran atau target group yaitu sekelompok orang atau organisasi dalam masyarakat yang akan menerima barang atau jasa yang akan dipengaruhi perilakunya oleh kebijakan. Karakteristik yang dimiliki oleh kelompok sasaran seperti: besaran kelompok, jenis kelamin, tingkat pendidikan, pengalaman, usia serta kondisi sosial ekonomi mempengaruhi terhadap efektivitas implementasi. Menurut Indiahono (2017:31) kelompok sasaran sebagai kumpulan individu-individu yang mendapatkan manfaat dari program anti kemiskinan, dalam kegiatan microfinance, ternyata perilakunya dapat mempengaruhi kinerja program itu sendiri.

Kelompok sasaran dalam program pinjaman dana bergulir, yaitu pelaku Usaha Mikro, Kecil dan Menengah di Kabupaten Banyumas. Dimana pelaku UMKM tersebut harus tergabung dalam satu kelompok yang terdiri dari berbagai jenis usaha dan terlembaga. Pelaku usaha mikro atau usaha kecil harus sudah memiliki usaha dan tidak fiktif. Dalam satu kelompok pelaku UKM harus mempunyai legalitas kelompom berupa nama kelompok, buku tamu, daftar nama anggota kelompok, buku pertemuan rutin, dan stempel kelompok.

Dalam implementasi program pinjaman dana bergulir untuk dapat menentukan sasaran program secara tepat sesuai dengan yang telah ditetapkan dalam mekanisme pelaksanaan program, sebelumnya dilakukan sosialissi kepada masyarakat terutama mereka yang bergerak dalam usaha ekonomi mikro dan kecil. Kemudian pihak implementor melakukan identifikasi sasaran program dengan melaksanakan survei turun ke lapangan, sebelum ditetapkan sebagai kelompok penerima program pinjaman dana bergulir. Menurut Getu (2000:152) yang berjudul "Social Capital: Implications for Development Theory, Research and Policy" mengemukakan bahwa pengembangan usaha mikro pada dasarnya berkaitan dengan pemberian kredit dan pelatihan keuangan yang berkaitan dengan pengusaha mikro miskin sehingga memungkinkan mereka untuk meningkatkan usaha mikro dan menciptakan lapangan kerja dan pendapatan bagi mereka sendiri dan komunitas mereka.

Terkait dengan pelaksanaan program pinjaman dana bergulir bagi UMKM di Kabupaten Banyumas, dana bergulir yang diperoleh sangat membantu perkembangan usaha yang dimiliki para pelaku UMKM penerima 
program. Banyak dari penerima program pinjaman dana bergulir yang semakin berkembang usahanya setelah menerima dana bergulir. Dengan semakin berkembangnya usaha yang dimiliki berdampak pada semakin meningkatnya kesejahteraan keluarga.

\section{Komitmen Penerima Program untuk Membayar Angsuran Kredit}

$\begin{array}{crc}\text { Sejalan } & \text { dengan } & \text { hasil } \\ \text { penelitian } & \text { terdahulu } & \text { yang }\end{array}$
dilakukan oleh Satriyawan Abu Yasid (2015:9) mengemukakan bahwa implementasi program bantuan dana bergulir pada Badan Layanan Umum Daerah Di Kota Kendari telah dilaksanakan tetapi dalam perjalannnya belum dilakukan secara optimal. Hal ini ditandai dengan adanya beberapa faktor yang menjadi kendala atau penghambat implementasi program yaitu struktur kerja yang sangat biroratif, strategi implementasi yang kurang efektif, koordinasi yang belum maksimal, tidak adanya kepatuhan nasabah dalam mengembalikan dana bergulir yang diterima, serta sumber daya yang sangat terbatas yakni kualitas staf yang masih rendah dan sarana prasarana yang kurang memadai.

Secara teoritis bahwa kepatuhan adalah sikap atau perubahan sikap yang biasa terjadi dalam setiap aktifitas manusia termasuk dalam proses implementasi kebijakan. Perubahan sikap baik itu dari implementor maupun terget atau kelompok sasaran program menjadi salah satu hambatan dalam menjalankan kebijakan. Kepatuhan nasabah atau penerima program dalam mengembalikan dana bergulir yang telah diterimanya turut menentukan keberhasilan implementasi program pinjaman dana bergulir. Apabila penerima program memiliki komitmen untuk membayar angsuran kredit secara rutin maka tidak akan menimbulkan terjadinya kredit macet dalam implementasi program pinjaman dana bergulir. Pengembalian angsuran kredit secara individu atau kelompok merupakan bentuk kesediaan atau komitmen dari sasaran suatu kebijakan yang dapat menentukan keberlanjutan atau perguliran dana bergulir kepada kelompok lain yang membutuhkan.

Faktor kendala atau penghambat dalam implementasi program pinjaman dana bergulir bagi pelaku Usaha Mikro, Kecil dan Menengah di Kabupaten Banyumas, yaitu ketidakpatuhan kelompok sasaran sebagai penerima program dalam mengembalikan angsuran kredit dari dana bergulir yang diterimanya secara rutin. Sehingga, menimbulkan adanya kredit macet dalam pelaksanaan program pinjaman dana bergulir.

Ketidakpatuhan penerima program dalam membayar angsuran kredit mengakibatkan terjadinya tunggakan angsuran dalam pengembalia angsuran kredit. Berdasarkan hasil 
penelitian peneliti mencatat, bahwa secara umum kemacetan atau keterlambatan pengembalian pinjaman dana bergulir selama ini terjadi diakibatkan karena kemacetan usaha yang mereka miliki. Dengan kemacetan usaha yang dimiliki berdampak pula pada kemacetan pengembalian angsuran kredit pada pengelola program.

\section{Berdasarkan}

pembahasan di atas dapat ditarik kesimpulan, bahwa pelaksanaan program pinjaman dana bergulir bagi pelaku Usaha Mikro, Kecil dan Menengah di Kabupaten Banyumas masih terkendala dalam kepatuhan penerima program dalam mengembalikan angsuran kredit. Kebanyakan penerima program yang tidak konsisten dengan waktu atau jadwal pengembalian dana bergulir atau keterlambatan dalam mengembalikan angsurannya adalah pelaku UKM yang bergerak di sektor perdagangan dalam berbagai jenis usaha. Mereka tidak bisa mengangsur angsuran kredit dikarenakan usaha yang dimiliki bangkrut atau berhenti berusaha, dikarenakan berbagai penyebab antara lain semakin meningkatnya persaingan usaha baik di tingkat lokal maupun global dan rendahnya daya inovasi. Selain pelaku UKM yang sudah tidak memiliki usaha, pelaku UKM penerima program yang usahanya masih berjalan juga bermasalah dalam hal pengembalian angsuran. Hal ini dikarenakan kegagalan dalam melakukan manajemen keuangan yang mengakibatkan kewajiban untuk mengangsur terlupakan.

Penyebab lain dari macetnya kredit pinjaman dana bergulir dalam pengimplementasian program pinjaman dana bergulir bagi UMKM di Kabupaten Banyumas, yaitu adanya anggapan atau persepsi dari penerima program yang menyebutkan bahwa dana bergulir tersebut sebagai salah bagian dari dana ghibah. Sehingga, penerima program tidak berkewajiban untuk mengembaliakan kembali dana bergulir yang diperolehnya kepada pemerintah. Berikut ini gambar keterkaitan antara karakteristik aparat pelaksana dan karakteristik kelompok sasaran dalam implementasi program pinjaman dana bergulir bagi UMKM di Kabupaten Banyumas. 


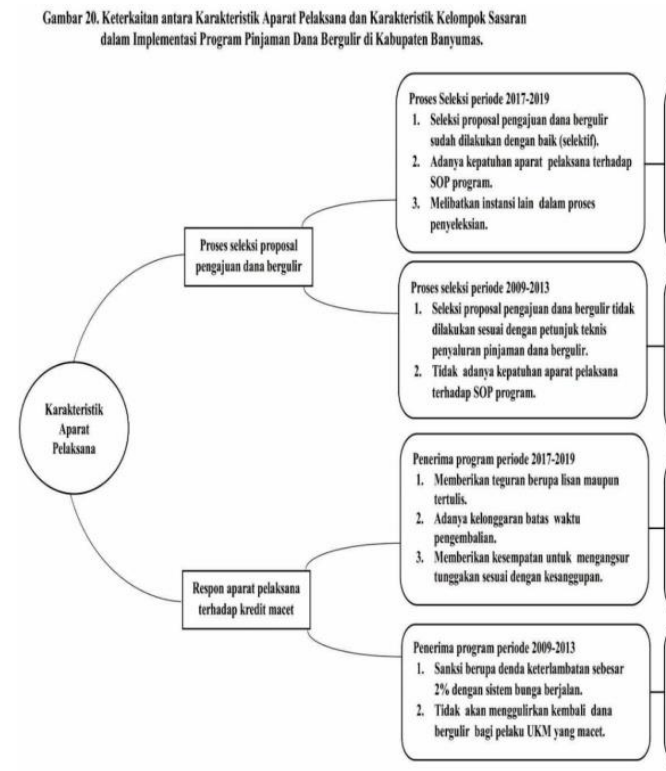

KESIMPULAN DAN IMPLIKASI

Dalam rangka pengembangan UMKM di Kabupaten Banyumas melalui program pinjaman dana bergulir terbukti dapat meningkatkan perkembangan usaha yang dimiliki pelaku UMKM yang pada akhirnya bardampak pada pengentasan kemiskinan di masyarakat. Realitas pelaksanaan program di lapangan ditentukkan oleh karakteristik aparat pelaksana dan karakteristik kelompok sasaran. Untuk melihat karakteristik aparat pelaksana dapat dilihat dari dua hal, yaitu proses seleksi pengajuan pinjaman dana bergulir dan respon aparat pelaksana terhadap kredit macet pada kelompok sasaran. Sedangkan, perihal karakteristik kelompok sasaran dilihat dari dual hal, yaitu kriteria pelaku UMKM penerima program dan komitmen penerima program untuk membayar angsuran kredit.

Proses seleksi yang dilakukan dengan selektif dan adanya kepatuhan pada SOP program serta

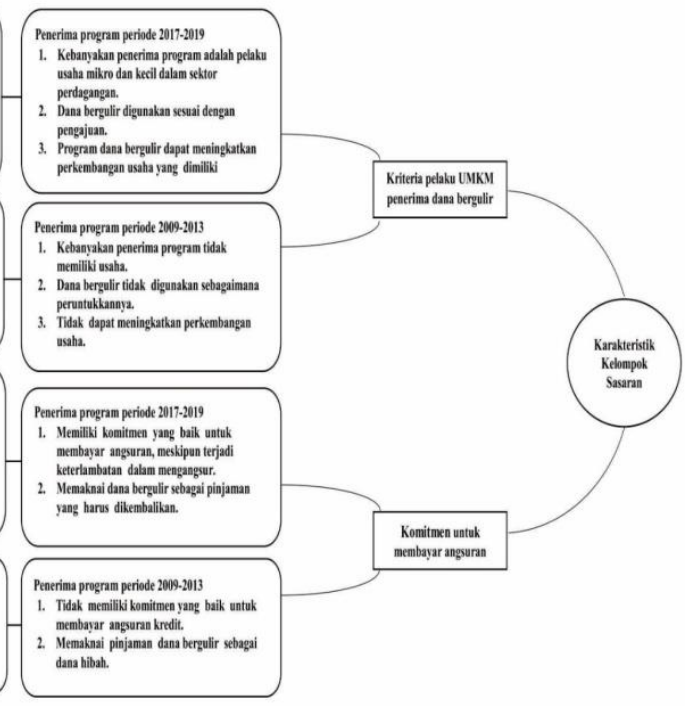

melibatkan kerjasama dengan instansi terkait menghasilkan karakteristik kelompok sasaran yang baik pula. Kelompok sasaran ini yaitu pelaku usaha mikro yang bergerak di sektor perdagangan. Setelah menerima dana bergulir oleh pelaku UKM penerima program digunakan dengan baik untuk keperluan usaha. Sehingga, dana bergulir memiliki manfaat yang besar dalam mengembangkan usaha yang dimiliki. Hal ini berlaku bagi penerima program periode terbaru, yaitu 20172019. Sedangkan, bagi penerima program periode awal tahun 20092013 proses seleksi yang dilakukan aparat pelaksana tidak dilakukan dengan baik sesuai dengan petunjuk teknis yang ada. Tidak adanya kepatuhan aparat pelaksana terhadap SOP program, menghasilkan karakteristik kelompok sasaran yang tidak baik pula. Penerima program kebanyakan adalah bukan pelaku usaha, melainkan warga biasa yang mengajukan pinjaman. Dalam penggunaan dana bergulir, pelaku UKM tersebut juga tidak 
menggunakan dana bergulir sebagaimana peruntukkannya. Sehingga, dapat dikatakan program dana bergulir ini tidak tepat sasaran.

Perihal pengembalian angsuran kredit bagi penerima program tahun 2017-2019, mereka memiliki komitmen yang baik untuk membayar angsuran kredit setiap bulannya. Meskipun masih terjadi keterlambatan dalam mengangsur, mereka memiliki itikad yang baik untuk segera melunasi tunggakan angsuran yang ada. Hal ini dikarenakan mereka memaknai pinjaman dana bergulir sebagai pinjaman yang harus dikembalikan. Adanya itikad yang baik tersebut, membuat pemerintah memberikan kelonggaran waktu dalam mengangsur. Sedangkan, bagi pelaku UKM penerima program tahun 20092013 tidak memiliki komitmen yang baik dalam mengangsur. Hal ini dikarenakan mereka memaknai pinjaman dana bergulir tersebut sebagai dana ghibah yang tidak seharusnya dikembalikan kepada pemerintah. Adanya itikad yang tidak baik dari pelaku UKM penerima program, respon pemerintah yaitu tidak akan menggulirkan kembali dana bergulir bagi pelaku UKM yang bersangkutan. Berikut ini gambar keterkaitan antara karakteristik aparat pelaksana dengan karakteristik kelompok sasaran dalam implementasi program pinjaman dana bergulir di Kabupaten Banyumas.

Pelaksanaan program pinjaman dana bergulir bagi UMKM di Kabupaten Banyumas sejak pertama digulirkan hingga saat ini, permasalahan mengenai kredit macet dalam pengembalian angsuran dan tunggakan angsuran kredit masih saja terjadi. Kredit macet tersebut tidak pernah dapat diselesaikan dengan tuntas oleh pengelola program.
Penyebab kredit macet pada penerima program dikarenakan berbagai hal, diantaranya penggunaan dana bergulir yang tidak sesuai dengan peruntukkannya, kegagalan dalam melakukan manajemen keuangan, dan kemacetan usaha yang dimiliki.

Berkaitan dengan permasalahan kredit macet dalam implementasi program pinjaman dana bergulir bagi UMKM di Kabupaten Banyumas, maka Dinas Tenaga Kerja, Koperasi dan UKM diharapkan agar lebih mengoptimalkan pengawasan terhadap pelaku UMKM penerima pinjaman dana bergulir yang masuk dalam kategori macet. Dengan cara mengkerahkan semua aparat pelaksana yang ada untuk ikut serta di dalam kegiatan turun lapangan untuk monitoring dan evaluasi setelah dana bergulir itu disalurkan.

\section{DAFTAR PUSTAKA}

Andri Yuni Astuti. "Pinjaman Bergulir, Kredit Macet, Serta Efek Moderasi Pendampingan". Upajewa Dewantara, Universitas Sarjanawiyata Tamansiswa, t.t. hlm.3.

Asmara, Fibri Chyntia. 2018. "Implementasi Bantuan Dana Bergulir Bagi Pelaku Usaha”. Fakultas Ilmu Sosial dan Ilmu Politik, Universitas Maritim Raja Ali Haji.

Ayusia, Sabhita Kusuma. 2016. "Kebijakan Pemerintah Daerah Kabupaten Banyumas Di Sektor UMKM". Jurnal Insignia. Universitas Jenderal Soedirman. Vol. 3, No. 2.

Aziz, Abdul dan Eko Wicaksono. 2016. "Analisis Skema Alternatif Kredit Program Untuk Usaha Mikro, Kecil dan 
Menengah".Jurnal Ekonomi dan Kebijakan Publik. Vol. 7, No. 2.

Candri Maharani Puspitasari. 2016. "Studi Efektifitas Dana Bergulir Pada Usaha Mikro di Kota Kendari", Skripsi, Kendari: Halu Oleo.

Chintya Fibri Asmara. 2018. "Implementasi Bantuan Dana Bergulir Bagi Pelaku Usaha”. Naskah Publikasi, Universitas Maritim Raja Ali Haji. hlm. 5.

Dita Wulandari, "Monitoring dan Evaluasi Distribusi Zakat Pada Yatim Mandiri Yogyakarta", Skripsi, Yogyakarta: UIN Sunan kalijaga Yogyakarta, 2015.

Dahnil Soekarno Hatta. 2014. "Lembaga Pengelola Dana Bergulir Koperasi dan Usaha Mikro, Kecil dan Menengah (LPDB-KUMKM) Sebagai Alternatif Lembaga Keuangan dalam Pemberdayaan Ekonomi Rakyat". Skripsi, Jakarta: UIN Syarif Hidayatullah.

Getu A. 2000. "Social Capital: Implications for Development Theory, Research and Policy". Fisheries an Aquaculture Journal. hlm. 152.

Hoo Helena Ayu Liani. 2017. “Dampak Pinjaman dan Bantuan Modal Kerja Terhadap Kinerja Usaha Studi Kasus UMKM Binaan KADIN Jawa Tengah". Jurnal. Jurusan Manajemen, FEB UNIKA Soegijapranata Semarang.

Husin Kusuma Wijaya. 2014. "Dampak Dana Bergulir Syariah (DBS) Pada Kinerja Baitul Maal Wa Tamwil (BMT)", Skripsi, Yogyakarta:
UIN Sunan Kalijaga

Yogyakarta.

Jariah, Ainun, Masjaya, Djumadi. 2016. "Evaluasi Penyaluran Bantuan Kredit Bergulir Pada Usaha Kecil dan Menengah di Kecamatan Tering Kabupaten Kutai Barat". Jurnal Administrative Reform. Vol. 4, No. 1.

Mulyono, Yon G., Ratna Verawati, Achmad Tjachja. 2015. "Penaruh Dana Bergulir Kementerian Koperasi dan UKM LPDB-KUMKM Terhadap Pengembangan Usaha Koperasi Simpan Pinjam Agribisnis Di Kabupaten Majalengka". Jur nal Agribisnis. Vol. 9, No. 1.

Nurmi, Yulis. 2017. "Pemanfaatan Dana Bergulir Simpan Pinjam Perempuan (SPP) Di Kelurahan Batu Bersurat Kecamatan XIII Koto Kampar". Jom FISIP. Vol. 4 No. 1.

Sirait, Bonar, 2009, Analisis Pengaruh Program Dinas Koperasi dan UKM Terhadap Perkembangan Koperasi, Usaha Mikro, Kecil dan Menengah (KUMKM) Di Provinsi Sumatera Utara, Tesis, Pasca Sarjana Unsud, Medan.

Sujarweni, Wiratna, Lila Retnani Utami, 2015. "Analisis Dampak Pembiayaan Dana Bergulir KUR (Kredit Usaha Rakyat) Terhadap Kinerja UMKM". Jurnal Bisnis dan Ekonomi (JBE). Universitas Respati Yogyakarta .Vol. 22 No.1: 1112.

Sumiyati dan Edy Suryadi. 2017. "Model Penyaluran Dana Dalam Optimalisasi 
Pengembangan UMKM Di Kabupaten Kubu Raya Provinsi Kalimantan Barat". JMM. Vol. 13, No. 2.

Suyono, Eko. 2018. "Pentingnya Sistem Pengendalian Manajemen dalam Pengelolaan Usaha Mikro Kecil dan Menengah di Kabupaten Banyumas. Jurnal Ilmiah Akuntansi. XVI (1), 64-83.

Trisnojuwono, Adi, Aida Vitayala S., Eko Ruddy Cahyadi. 2017. "Analisis Strategi Pembiayaan Usaha Mikro dan Kecil Melalui Dana Bergulir pada Lembaga Pengelola Dana Bergulir". Jurnal Manajemen IKM. Vol. 12 No. 2: 178-186. 